\title{
The Sharpness of Their Knives: Interrogating The Rhetoric of Rhetoric of Science
}

\author{
James Robert Allard \\ University of Waterloo
}

Alan G. Gross and William M. Keith, eds., Rhetorical hermeneutics: invention and interpretation in the age of science, Albany: State University of New York Press, 1997. vii +371 pages.

Henry Krips, J. E. McGuire, and Trevor Melia, eds., Science, reason, and rhetoric, University of Pittsburgh Press, 1995. vii +322 pages.

Jack Selzer, ed., Understanding scientific prose, University of Wisconsin Press, 1993. $x i+388$ pages.

\section{Introductions}

They speak authoritatively to our commonsense, to our intelligence, to our desire of peace or to our desire of unrest; not seldom to our prejudices, sometimes to our fears, often to our egotism — but always to our credulity. And their words are heard with reverence, for their concern is with weighty matters. (Conrad, p. xlvii)

These three collections have in common a desire to explore the limits of rhetoric of science, to probe its weaknesses and test its strengths; the editors leave it to their readers to judge if the business of rhetoric of science can continue in its usual way. ${ }^{1}$ Campbell and Benson observe, in a review of one of these books and with what I interpret as just a hint of regret, that it "returns us to the world of rhetorical analysts interested as much in the sharpness of their knives as in any object that (... ) might be used to carve" (p. 83), and this same observation rings true for each of these collec- 
tions. For these texts seek to do more than simply add to a growing body of work in rhetoric of science: they seek, in related though different ways, to critique it, to challenge it, and, ultimately, to force its practitioners to a new level of continual and critical self-reflexivity. But critiques and challenges are not always welcome.

Something else these collections share: disciplinary anxiety.

To be sure, anxiety may be a prerequisite for anyone in the humanities or social sciences these days, and many in rhetoric of science, particularly Gross and Keith, recognize and attempt to alleviate or at least explain their version of it; nevertheless, the anxiety here, and in rhetoric of science work generally, borders on paranoia. Part of my goal here, beyond examining these books, is to explore their relation to the field known as "rhetoric of science" in order to discover the source of that anxiety or paranoia.

To these ends, I treat these collections as collections: rather than trying to go into detailed discussions of my perceptions of the strengths and weaknesses of the individual essays in each collection (though some of this will inevitably occur), I discuss each text as a whole and allow them to speak to each other. Furthermore, I focus my attention in three directions. First, I examine each text in terms of its stated agenda. Each text offers, in the tradition of such collections, a clear statement of its perceived means and ends, its place relative to the field, where it fits, what it accepts, what it questions, and so on. Second, I examine a sampling of the critical reception of each text; that is, in terms of its ascribed agenda: how have others reacted to each volume, how effectively (according to reviewers) has each collection achieved its stated goals and objectives, and how important are those goals and objectives perceived to be. Finally, and by way of conclusion, I offer my own reaction to these three volumes: what did I take from them, how do I see them fitting into my own work, and so on. The true test of any theory or set of critical tools is its usefulness. What does "rhetoric of science" do for rhetoric and rhetoricians? for science and scientists? for anyone working in any field of inquiry that seeks to examine critically the relationship between language, truth, and power?

\section{Manufacturing Descent}

Who, in the enchanted regions of simile, metaphor, allegory, and description, can remember the plain order of things in this everyday world? (Baillie, p. 6)

While I do want to examine the texts in terms of their relationship to the field, there is little need for another genealogy of rhetoric of science ("... And Hanson begat Kuhn, and Kuhn begat Latour, and Latour begat ... "). ${ }^{2}$ Besides, the texts construct their own genealogies. The introductions and their relations to the essays they intro- 
duce (and, to a lesser degree, their relations to each other) demonstrate not only a sense of each text's relation to the field but also each text's reaction to the notion that there is "a" field to which they can relate.

Of the three, Understanding Scientific Prose is the only one that places itself explicitly in a genealogy, but Selzer does not immediately situate his volume within rhetoric of science. Instead, he notes that the title of his volume is an allusion to Cleanth Brooks and Robert Penn Warren's 1938 Understanding Poetry, a work that, in Selzer's words, "illustrated for an entire generation a method of practical criticism known as New Criticism" (p. 3). Selzer then fleshes out this genealogy by offering a list of "forebears" that begins with Edwin Black's Rhetorical Criticism: A Study in Method (1965) and ends with Roderick Hart's Modern Rhetorical Criticism (1990), "all of which," he contends, building on the allusion in his title, "seek to expand the repertoire of analytical methods at the disposal of rhetorical critics" (p. 4). He does discuss his text's relation to rhetoric of science, providing a brief and consequently sketchy overview of the field, but his immediate concern is with "introducing readers ... to new methods of analysis" (p. 3).

All of the essays in this collection investigate S. J. Gould and R. C. Lewontin's 1979 article "The Spandrels of San Marco and the Panglossian Paradigm: A Critique of the Adaptionist Programme," collectively working "to illustrate - and argue for - a pluralistic range of methods based on Foucault and Habermas, on gender and cultural studies, on deconstruction and reader response, on sociolinguistics and structuralism, on sociology and the stasis theory newly emerging from studies of classical rhetoric" (p. 7). A major undertaking, certainly, but a necessary one: as Selzer points out, " $[i] n$ the study of the rhetoric of science, we need analytical techniques as sophisticated and as powerful as the texts they are designed to describe, and we need opportunities to reflect on the adequacy of the methods we use to understand science" (p. 17).

This dual emphasis on pluralism and reflection is intriguing, for as much as Selzer says that he and his contributors "aim to further the effort of rhetorical criticism that has so much momentum today" (p. 3, emphasis mine), he is also saying that rhetoricians cannot live by rhetoric alone. Each of the volume's fourteen essays, while offering detailed and, in most cases, text-bound readings of "Spandrels," articulates not just a different method of study but a different object of study: from Bazerman's exploration of the Kristevan notion of intertext to Journet's Derridean deconstruction of "Spandrels" to Myers' use of politeness theory to Miller and Halloran's delicate balancing of classical rhetoric and Foucauldian discursivity, ${ }^{3}$ each essay in the volume seeks to read not only "Spandrels" but also the culture(s) that produced it and that it, in turn, produced. Oddly enough, despite Selzer's complaints 
elsewhere that Rhetorical Hermeneutics (presumably only one example in a long list of similar texts) offers "little concrete discussion of science with all its gab about interpretation" ("Scutinizing Science," p. 447), his own volume is never really about "science" at all: despite (perhaps because of) the precise focus on a single essay, "Spandrels" is quickly relegated to the background as the various methodologies and theories move to the foreground. But regardless of Selzer's own complaints about some texts' lack of concrete discussion of science and similar calls by others in the field for more traditional case studies, such movements hardly need be lamented: as Selzer's introduction and his titular allusion make clear, the essays in his volume are less about scientific prose than they are about cultivating the means to understanding, a more generative goal.

Gross and Keith's Rhetorical Hermeneutics seeks a similar goal, though its means are substantially different. The volume brings together and expands a debate first documented in the Summer 1993 Southern Communication Journal issue, a debate "provoked" by Gaonkar's wide-ranging critique of rhetoric of science. ${ }^{4}$ Gross and Keith offer this summary: "In a reversal of the usual topos, Gaonkar does not attempt to question whether the rhetoric of science has understood science properly, but whether it has sufficiently comprehended rhetoric" (p. 1). Gaonkar's critique is based on his perception of rhetoric as fundamentally productive rather than interpretive, on his questioning of classical rhetoric's notions of agency, on what he calls rhetoric's "thinness" as opposed to the "thickness" of deconstruction, psychoanalysis, and readerresponse, and on what he calls the "globalization" of rhetoric, the idea that if rhetoric is everywhere it is nowhere. Providing a similar kind of focus on a single essay, the remaining thirteen essays in the collection respond to Gaonkar (except the last, in which Gaonkar responds to his respondents), each in its own way taking up the challenge posed by Gaonkar to see the "emergence of the 'rhetoric of science' as a new and increasingly prominent subfield of study in our discipline [which] presents us with an extraordinarily fertile site to study the unfolding translative process" (p. 34) - the process of translating rhetoric as a "vocabulary of performance" into a "vocabulary of interpretation" (p. 32). All of the volume's contributors, whether they seek to extend Gaonkar's critiques, or attack them, or fortify rhetoric against them, embody and enact the same dual emphasis on pluralism and reflection. The editors' partitioning of the text into "Provocations" (Gaonkar), "Dissensions" (Leff, McCloskey, Campbell, Gross, Miller, and Willard), "Extensions" (Jasinski, Keith, Kaufer, Fuller, and King), and "Reflections/Refractions" (Farrell and Gaonkar again) recalls both Selzer's foregrounding of methodology and what Charles Arthur Willard calls, in another context, the "theoretical battle line [that] has formed at the center of the rhetoric of science" (p. 373). Gaonkar's critique is, indeed, provocative, but I am more than a 
little confused by the perceived need for dissent: Gross and Keith assert in their introduction that "Gaonkar teaches us to reflect on the consequences of our disciplinary haste" (p. 5), and many of the dissenters agree that his critiques warrant consideration. ${ }^{5}$ Gaonkar's critiques demand response, re-evaluation, and critique, but surely dissent is counter-productive. For if Rhetorical Hermeneutics, like Understanding Scientific Prose, hopes to complicate, extend, and ultimately strengthen rhetoric of science, such critiques are crucial. Similarly, many of the dissenting responses seek simply to defend rhetoric against Gaonkar's claims rather than re-examine the very idea of rhetoric. This is an important distinction: my reading of Gaonkar doesn't suggest a rejection of rhetoric or rhetoric of science, but a critical revision in light of issues raised by poststructural and postmodern critical theories. But this is not to suggest that poststructuralism or postmodernism are somehow better (or "thicker" or "denser") critical vocabularies; nor do I always agree with Gaonkar. He is sometimes too dismissive of rhetoric, particularly when it comes to the question of agency, and too willing to jump headlong onto poststructuralist bandwagons. What my reading of Gaonkar does imply, what it implores, is the need for the kind of constant and critical self-reflection these approaches require if rhetorical criticism and rhetoric of science are to continue to provide the kind of generative insight they promise. Where the volume succeeds is in the insistence that a sustained and self-conscious questioning of all aspects of rhetoric of science - including, perhaps especially, the questioning of "rhetoric" itself — is vital.

While Selzer's volume explores various methodologies that can contribute to rhetoric of science, and Gross and Keith's alternately attacks and defends, as Gaonkar's title puts it, "The Idea of Rhetoric in the Rhetoric of Science," Krips, McGuire, and Melia's Science, Reason, and Rhetoric is not as anxiously invested in rhetoric, though rhetoric does occupy a central place in the text. "The rhetorical perspective," they contend, "brings insight to the study of science not captured by history, sociology, philosophy, anthropology or heremeneutical [sic] analysis; that is, rhetoric can.occupy a 'clearing' that is obscured in these other approaches to science studies" (vii). The volume contains twelve essays, six of which are followed by comment or response essays, ${ }^{6}$ all of which, according to Krips, McGuire, and Melia, embody an approach that "eschews any attempt to transform the discourse of inquiry into a form that is friendly to rhetorical imperatives or to treat science as a particular praxis continuous with the sophistical tradition of rhetoric" (viii). This combination of essay and response builds reflection right into the fabric of the volume. Furthermore, the essays all seek to answer the 64 thousand dollar question: "What does the 'rhetoric' in 'rhetoric of science' add that cannot already be gotten from literary criticism, discourse analysis, hermeneutics, or cultural studies, not to mention philosophical relativism?" (xi). 
The question is not asked as a way to dismiss or belittle rhetoric, but as a way to reveal the possibilities of a rhetorical perspective when allowed to work in concert with others. While we might be able to say that all of these three texts ask a similar question, the other two are more interested in exploring what they see as the rhetorical aspects of discourse analysis, hermeneutics, and so on, in an effort to "rehabilitate" and defend rhetoric, than in truly advocating a pluralistic approach, despite the fact that pluralism figures prominently in all three.

Science, Reason, and Rhetoric avoids (maybe hides) the disciplinary anxieties better than the others (though the editors' claim to "offer this volume with the aim of showing the importance of rhetorical dimensions in the enterprise of science" [xviii] betrays an anxiousness to justify the project). Because of this move, and because it explicitly advocates a variety of approaches that incorporate rhetoric instead of developing approaches to incorporate into rhetoric, 1 confess an initial reluctance to find fault with the volume. I nodded vigorously when I read that the text and the approaches developed in it maintain "a pluralistic and antihegemonic stance" that attempts to "integrate rhetorical elements into a larger whole that contains as well accounts of science that are patently not rhetorical" (viii). But I also shook my head gravely when I read that "science is seen as a special type of human activity" (xviii, emphasis mine), for in such formulations "science" becomes hallowed ground onto which only equally "special" people can tread. Gross has already eloquently critiqued this privileging of science in an exchange with McGuire and Melia.? The anxiety that drives the desire to maintain science as a special area of human activity rather than as an activity open to the participation and scrutiny of all who care to do so, to see it as a particular site of privilege, is considerably more dangerous than the anxiety that drives others to see rhetoric as an all-encompassing, all-pervasive master trope. The volume does proceed with examinations of science and explorations of the ways science can and needs to be examined, and not all of its essays are willing to reinforce or even entertain the idea of science as a privileged site; Campbell's and Kitcher's essays in particular, are free of such preoccupations. Even with these anxieties, this collection, like Understanding Scientific Prose and Rhetorical Hermeneutics, attends to the multiple ways that rhetoric of science needs to be questioned, complicated, revised, and questioned again if it is going to thrive.

\section{Influencing Anxieties}

The critic must know what effect it is his object to produce; and with a view to this effect must he weigh his words. (Coleridge, p. 238) 
These three collections actively seek to engage, even confront, rhetoric of science, its texts, and its practitioners as much as they seek to explore specific (inter)disciplinary questions or examine particular aspects of science, its texts, and its contexts. And, of course, such engagements and confrontations almost never go unanswered. All three collections have generated a tremendous amount of interest in the relevant journals, interest that ranges from glowing praise to glowering rage. The responses have one thing in common, though. They manifest the same general anxiety-cum-paranoia that spawned and informs these volumes.

The shape of Selzer's volume, its use of a single object text, provides an interesting though hardly unique twist to the traditional case study. As I discussed earlier, such an approach backgrounds the object text and foregrounds the critical methodologies. Campbell and Benson's review articulates this point clearly: "[b]ecause of the unity given the volume by its focus on one essay, the reader is able to see each version of rhetorical method as a facet of a complex but coherent alternative perspective to understanding science" (p. 84). However, Campbell and Benson's suggestion that each essay presents a "version of rhetorical method" (emphasis mine) and that these versions somehow constitute a "coherent" perspective is characteristic of the anxiety haunting rhetoric of science. Gross, in "Science and Culture," argues almost against Campbell and Benson that "Understanding Scientific Prose says little more than that science is, to some extent, rhetoric. At this late stage, this observation cannot be enough. In the absence of new ideas and a well-defined research agenda, rhetorical studies of science will legitimately flounder" (p. 181), but the end result is the same. Gross, too, manifests the same anxiety, perhaps more so than most; in my reading of Selzer's volume, rhetoric is but a voice (albeit a powerful one) in a chorus, ${ }^{8}$ and not, as Gross would have us believe, the song every chorus is singing. Gross is one of the most passionate and erudite in the field; but, as Lynette Hunter puts it, in this volume, "he still works within a worldview that believes in the possibility of true communication" (186). This belief is one of the key factors ensuring that Gross, like Campbell and Benson, is more concerned with Selzer's use (and maybe abuse) of rhetoric than any of them are with seeing the potential value in Selzer's work. Understanding Scientific Prose is praised or blamed precisely for its contributions or lack thereof to rhetoric of science. Selzer's volume seeks not to present a "coherent alternative" or to say that "science is, to some extent, rhetoric," but to begin to recognize the possibility of a truly interdisciplinary approach to science studies - an approach perhaps led by rhetoric and rhetoricians, but one made possible by the tools and methodologies from a wide range of disciplines. 
Rhetorical Hermeneutics has received a great deal of coverage in the journals; however, inevitably, that coverage is often less about the volume itself than about the initial debate that prompted its publication in the first place. This debate, about the field's ( any field's) "appropriate sphere and circumference" (Selzer, "Scrutinizing" 448), is ages old, but it was sparked in this instance by Gaonkar's poststructuralist/ postmodernist-inspired critique of classical rhetoric. Lambert summarizes Gaonkar's argument in an interesting - and interested - manner:

Gaonkar attacks the humanist paradigm that governs rhetorical criticism of scientific literature, especially its inadequate model of the rhetor as the conscious agent who chooses and invents discourse in a field where institutional pressures and discourses dominate individual agency (p. 512).

As I have already made clear, Gaonkar's critique of the idea of agency in this particular realm echoes my own concerns; however, neither Gaonkar's essay nor its many dissensions and extensions are, strictly speaking, about agency, for agency is merely one facet of the critique and its responses. But Lambert's comments, like Selzer's, are characteristic: because of the nature of the questions posed in Rhetorical Hermeneutics, questions of agency and propriety in the broadest senses, reviewers seem to want to take sides, to profess their own dissent or to offer their own support or extension. Selzer, for one, goes so far as to virtually dismiss the volume in terms of its contributions to rhetoric of science: he contends that "the book will be only marginally interesting to those seeking to understand science as a cultural and rhetorical practice," though he concedes, with what seems to me a great deal of reluctance, that "it will be widely cited by those who are drawn to the larger disciplinary question that it addresses" ("Scrutinizing," p. 449). Again, the concern here is with the text's investment in rhetoric, not with its investment in furthering the efforts of science studies; strange, because the volume's aim is precisely to articulate the ways rhetoric of science can be made more productive. As I have said, and will continue to say, only a critical and constant re-examination of such "larger disciplinary question[s]" (the plural is crucial here) will allow anyone at anytime to "understand science as a cultural and rhetorical practice."

The critical reception of Science, Reason, and Rhetoric is somewhat more difficult to assess with any accuracy: I know of only one appraisal, Willard's brief review in the Quarterly Journal of Speech. (This fact perhaps says more about its "reception" than any review ever could, given especially that the book appeared two years before the more widely reviewed Gross and Keith volume.) But Willard's comments may be enough to allow us to speculate fruitfully about the role of the volume in the immediate future of the field. Willard dutifully acknowledges the volume's stated agenda when 
he observes that "[i]t is about rhetoric's niches amid the varieties of knowledge production and attendant human contexts of science" (p. 370). But he also recognizes what he calls its "deeper agenda" (p. 370), the demand for critique, for self-reflection, and for the recognition that disciplinary anxieties should not limit but intensify this critique and self-reflection: "Every argument meant to coax the rhetorically-challenged across the bridge [between rhetoric of science and philosophy of science] also calls for a course correction with the rhetoric of science" (pp. 370-1). The volume puts its money where its mouth is by including the comment/response essays, and, while not all of them are as critical as they might be, the immediacy of the responses is a first crucial step towards the kind of "course correction" the editors seek to foster. Willard knows, however (as do Krips, McGuire, and Melia), that such an agenda will be vehemently resisted in some quarters, for such a corrective will be seen, alas, as yet another attack against rhetoric, rather than the complicating and strengthening move it is. It should be interesting to follow the development of Willard's notso-metaphorical "theoretical battle lines" (p. 373) - if, in fact, others within the field come to realize the necessity and benefits of the exercise. I, for one, truly hope they do, for as Willard points out, "[w] ith luck and civility [note the crucial proviso], it will be a dispute that strengthens both positions by probing their flaws, testing their strengths, and perhaps finding points of agreement" (p. 373).

\section{Beyond "The Rhetoric of Rhetoric of Science"}

Great is language.... it is the mightiest of the sciences. (Whitman, p. 41)

Anxiety, in short, has taken rooms in the House of Rhetoric. Gross and Keith say it best: "The worry that rhetoric is, or has been, suppressed reflects a real disciplinary anxiety: the worry that one's discipline might be marginalized or become, like the profession of the Roman haruspex or the modern astrologer, no longer intellectually intelligible" (p. 19). But as much as these three volumes are concerned with rhetoric and thus reflect, in varying degrees the anxieties often associated with it, there are salutary breezes: they are also concerned with exploring (again, in varying degrees) the ways various other tools, methodologies, and theories can make rhetoric stronger. Such claims are not new; Harris stresses that "[a]nyone with more than a passing interest in the field is obliged to read widely in all the contemporary disciplines that investigate the flow of discursive influence in the sciences" (xxv). But reading cannot be enough. As I have been arguing throughout, where these texts succeed best is in their (sometimes too quiet) insistence on pluralism and reflection. Understanding Scientific Prose, while certainly looking to further the ends of rhetorical criticism, argues the need to import and complicate aspects from a range of disciplines 
into the continuing work of rhetoric of science. Rhetorical Hermeneutics, in its own way defending rhetoric, articulates brilliantly the need for critical self-reflection, for the careful and continual re-evaluation of "rhetoric" and its methods. Science, Reason, and Rhetoric, advocating but not necessarily demanding a kind of defense of rhetoric, shows how rhetoric can fit easily and productively into a varied and powerful critical toolkit.

Although many in the field, like Harris and those involved in these three texts, argue that rhetoric of science is already "pluralistic" (Harris xxxvi), that pluralism is too often lost in the perceived need to defend rhetoric's involvement. My heading, "Beyond 'The Rhetoric of Rhetoric of Science," doesn't mean to imply that rhetoric of science is passé, that we need to abandon the rhetorical tradition in favour of something "newer." Instead, I suggest that we need to focus less on justifying and re-justifying rhetoric and more on doing what rhetoric is supposed to do: produce texts and discourse, generate ideas and controversy.

In the end, regardless of what some rhetoricians of science seem to want to construct as popular opinion, rhetoric - much less rhetoric of science - is in no danger. Certainly, "rhetoric" as a term has taken something of a scholarly beating, with various entities seeking to employ it, critique it, dismiss it, and then employ it again without ever having any knowledge of or training in its long traditions. But, while rhetoric may have had the misfortune of a much more public flogging, its fate has been no worse than that of "literature," "culture," "theory," even "science" - all of which have, in my opinion, been strengthened by the careful and critical re-evaluations carried out over the last two or three decades. Like these others, as a discipline or set of disciplines, as practice or practices, rhetoric will be just fine. And rhetoric of science, as long as it continues with the type of self-conscious, self-reflexive activities advocated by and embodied in these three texts, will be even better.

\section{Notes}

1 I borrow and adapt this last comment from Gross and Keith's introduction, for I believe that with some minor substitutions their comments can apply equally to all three volumes under review here: "This broader constituency may judge for itself whether the issues raised by Gaonkar, and challenged, amplified, and modified by his respondents, speak directly to their concerns. In our view, they do. They may judge also whether, having read this volume, they can continue to work in their usual way. In our view, they cannot" (pp. 1-2).

2 I adopt the term "genealogy" here from Foucault, and although it has been variously defined and discussed by Foucault and his many interpreters, l prefer the working definition he offers in "Two Lectures": "Let us give the term genealogy to the union of erudite knowledge and local memories which allows us to establish a historical knowledge of struggles and to make use of this knowledge tactically today" (p. 83). Three genealogies that have been particularly useful to me are found in Campbell and Benson's "The 
Rhetorical Turn in Science Studies," especially the literature review in the first note; in Harris's Landmark Essays on Rhetoric of Science: Case Studies, both the introduction and the extensive bibliography; and in Melia's "And Lo the Footprint ... Selected Literature in Rhetoric of Science." One could easily add the introductions and bibliographies in Bazerman's Shaping Written Knowledge (1988), Gross's The Rhetoric of Science (1990), and Prelli's A Rhetoric of Science (1990) among a number of other useful and now "canonical" sources.

3 Other approaches in the text include Wells' reading of "Spandrels" in terms of Habermas" notions of modernity and narration, Hendl's adaption of culture theorists such as Stuart Hall and Raymond Williams, Rosner and Rhoades's Donna Haraway-inspired gender critique, Winsor's analysis of Gould and Lewontin's reception, Lyne's Burkean reading of rhetorical invention, Fahenstock's use of "classical rhetoric, reincarnated in The New Rhetoric" (p. 160), Gragson and Selzer's and Charney's deployment of different aspects of reader-response theory, and Couture's version of M.A.K. Halliday's systemic functional analysis.

4 Many of the essays in the volume (including those by Gaonkar, Gross, Campbell, Leff, and Fuller) are revised versions of essays that appeared in the now infamous (in rhetoric of science circles, at least) 1993 Southern Communication Journal.

5 I am, though, disappointed in McCloskey's repeated ad hominem attacks against Gaonkar (she calls his arguments "self-deprecating bluster" [p. 103] and refers to his "unconscious attachment to the sneer" [p. 110]) in an apparent "critique" of his arguments and a defense of rhetoric. Such responses are not only unnecessary, they are, more importantly, unscholarly.

6 The essays by Kitcher, Felday, Pinch, Campbell, Lyne, and Beer are all followed by commentaries (Salmon on Kitcher, Machamer on Felday, Krips on Pinch, Lennox on Campbell, Bradie on Lyne, and Melia on Beer).

7 See, for example, Gross's "Rhetoric of Science Without Constraint" and McGuire and Melia's "The Rhetoric of the Radical Rhetoric of Science."

8 The metaphors of the voice and the chorus here are not particularly happy ones, for they both imply the kind of coherence (in rhetoric and in science studies) that I argue against in Campbell and Benson.

\section{References}

Baillie, Joanna. "Introductory discourses." Plays on the passions. The dramatic and poetical works of Joanna Baillie. $2^{\text {nd }}$ ed. London: Longman, 1853. 1-18.

Bazerman, Charles. Shaping written knowledge: The genre and activity of the experimental article in science. Madison: $U$ of Wisconsin P, 1988.

Black, Edwin. Rhetorical criticism: A study in method. New York: MacMillan, 1965.

Campbell, John Angus, and Keith R. Benson. "The rhetorical turn in science studies." Quarterly journal of speech 82 (1996): 74-91. 
Coleridge, Samuel Taylor. Biographia literaria. 1817. Ed. George Watson. Toronto: Everyman, 1965; rpt. 1980.

Conrad, Joseph. Preface. The nigger of the "narcissus". 1897. Ed. Cedric Watts. Markham, ON: Penguin, 1988. xlvii-li.

Foucault, Michel. "Two Lectures." 1977. Power/Knowledge: selected interviews and other writings 1972-1977. Ed. Colin Gordon. New York: Pantheon, 1980. 78108.

Gross, Alan G. The rhetoric of science. Cambridge: Harvard UP, 1990.

—. "Rhetoric of Science Without Constraints." Rhetorica 4.4 (Autumn 1991): 28399.

—. "Science and Culture." American literary history 7 (1995): 169-86.

Harris, Randy Allen, ed. Landmark essays on rhetoric of science: case studies. Mahwah, NJ: Hermagoras P, 1997.

Hart, Roderick. Modern rhetorical criticism. Glenview, IL: Scott, Foreman/Little, Brown, 1990.

Lambert, Larry. Rev. of Rhetorical hermeneutics: invention and interpretation in the age of science. Ed. by Alan G. Gross and William M. Keith. Quarterly journal of speech 84.4 (Nov. 1998): 511-4.

McGuire, J. E. and Trevor Melia. "The Rhetoric of the Radical Rhetoric of Science." Rhetorica 4.4 (Autumn 1991): 301-16.

Melia, Trevor. "And Lo the Footprint ... Selected Literature in Rhetoric of Science." Quarterly journal of speech 70 (1984): 303-34.

Prelli, Lawrence J. A rhetoric of science. Carbondale, IL: U of Southern Carolina P, 1990.

Selzer, Jack. "Scutinizing Science." College english 60.4 (April 1998): 444-50.

Whitman, Walt. "Great are the myths." Leaves of Grass. 1855. Ed. Malcolm Cowley. Toronto: Penguin, 1959; rpt. 1986. 142-5.

Willard, Charles Arthur. Rev. of Science, reason, and rhetoric. Ed. by Henry Krips, J. E. McGuire, and Trevor Melia. Quarterly journal of speech 83 (1997): 370-3. 